\title{
SISTEM KONTROL SUHU PADA MESIN TETAS TELUR AYAM BURAS HEMAT ENERGI DAYA TETAS OPTIMAL
}

\author{
Maria Dolorosa Badjowawo ${ }^{1}$ dan Daud Obed Bekak ${ }^{2}$
}

\begin{abstract}
Abstrak :
Ayam Buras merupakan jenis ternak yang banyak dipelihara masyarakat diindonesia pada umumnya khususnya kelompok ternak ayam buras di Desa Noelbaki Kecamatan Kupang Tengah Kabupaten Kupang Propinsi Nusa Tenggara Timur. Usaha ternak yang dilakukan bertujuan dapat meningkatkan ekonomi rumah tangga. Kenyataanya belum dapat memperdayakan ekonomi rumah tangga bagi kelompok ternak ayam buras karena proses kembang biaknya bersifat alamiah. Solusinya adalah pemodelan mesin tetas telur ayam buras yang dapat meningkatkan daya tetas telur ayam buras berkapasitas 100 butir telur ayam buras. Keunggulan mesin tetas telur ayam buras hasil penelitian adalah; daya tetas optimal mencapai 95\%, suhu merata dan stabil, daya terpakai 50,6 watt.
\end{abstract}

Kata Kunci: Daya tetas optimal, hemat energi

\section{PENDAHULUAN}

Ayam Buras merupakan jenis ternak yang banyak dipelihara masyarakat di Indonesia pada umumnya khususnya kelompok ternak ayam buras di Desa Noelbaki Kecamatan Kupang Tengah Kabupaten Kupang Propinsi Nusa Tenggara Timur, untuk meningkatkan income rumah tangga. Realitanya peternak ayam buras belum dapat meningkatkan ekonomi rumah tangga karena proses kembang biaknya bersifat alamiah, yaitu: dierami induk ayam buras. Kapasitas maksimal hasil tetasan kurang lebih 10 butir telur (Suprapto dkk, tt, www. Wikipedia 2011). Untuk mengatasi proses kembang biak ayam buras secara alamiah dan dapat meningkatkan income rumah tangga peternak ayam buras, diperlukan teknologi mesin tetas yang dapat mengganti proses penetasan secara alamiah.

Masalah utama pada mesin penetas telur ayam pada umumnya termasuk mesin tetas telur ayam buras adalah masalah sistem kontrol suhu panas yang merata dan stabil pada ruang rak telur mesin tetas. Suhu yang sesuai untuk pertumbuhan embrio telur ayam pada umumnya termasuk telur ayam buras berkisar diantara suhu $38^{\circ} \mathrm{C}-40^{\circ} \mathrm{C}$. Mesin tetas yang sudah ada dipasaran bahkan sudah digunakan konsumen menggunakan elemen pemanas yang ditempatkan pada pusat ruang rak telur mesin tetas sehingga penyebaran suhu panas tidak merata dan tidak stabil. Suhu panas lebih panas dekat dengan elemen pemanas jika dibandingkan dengan suhu panas yang jauh dengan elemen pemanas sehingga telur ayam yang ditetas hasilnya tidak optimal atau bahkan gagal total. Untuk mengatasi penyebaran suhu panas yang tidak merata dan tidak stabil dalam ruang rak telur mesin penetas telur ayam menggunakan kipas angin atau fan (wire) menyebabkan sangat boros energi. Solusinya adalah membuat mesin tetas telur ayam buras dengan sistem kontrol suhu merata dan stabil hemat energi daya tetas optimal. Daya tetasnya

Badjowawo' ${ }^{1}$ an Bekak², Adalah Dosen Teknik Elektro Politeknik Negeri Kupang 


\section{Jurnal Ilmiah FLASH Volume 1 Nomor 1 Desember 2015}

dapat mencapai 95\%-100\% dengan asumsi telur yang akan ditetas adalah hasil pembuahan dan dalam kondisi normal.

\section{KAJIAN PUSTAKA}

\subsection{Kontrol Suhu}

Sistem kontrol penyebaran suhu atau temperatur panas yang merata dan stabil di dalam ruang rak telur mesin tetas telur ayam buras sangat diperlukan untuk menghasilkan daya tetas telur ayam buras secara optimal. Pemanas yang digunakan didalam mesin penetas pada umumnya menggunakan elemen pemanas. Suhu panas yang dihasilkan didalam ruang rak telur mesin tetas tidak merata. Suhu yang jauh dengan elemen pemanas lebih rendah jika dibandingkan dekat dengan elemen pemanas. Untuk penyebaran suhu panas yang tidak merata menggunakan kipas angin. Penggunaan kipas angin untuk penyebaran suhu panas yang merata terjadi pemborosan energi.

\subsection{Sistem Regulator}

Sistem regulator outomatik adalah sistem kontrol berumpan - balik dengan masukan acuan atau keluaran yang diinginkan konstan atau berubah terhadap waktu dengan lambat dan tugas utamanya adalah menjaga keluaran yang sebenarnya pada harga yang diinginkan dengan adanya gangguan (Katsuhiko Ogatha, 1995).Sistem pemanas ruangan dengan termostat sebagai kontrolernya adalah sebuah kontrol sistem regulator outomatik. Pada sebuah kontrol sistem regulator outomatik, penyetelan termostat (temperatur yang diinginkan) dibandingkan dengan temperatur ruang yang sebenarnya. Perubahan temperatur di luar ruangan adalah gangguan pada sebuah kontrol sistem regulator outomatik. Sasarannya adalah menjaga temperatur ruang yang diinginkan meskipun terjadi perubahan temperatur diluar ruangan. Contoh sistem regulator outomatik, diantaranya adalah pengontrolan outomatik dari tekanan dan besaran listrik (tegangan listrik, arus listrik, frekwensi listrik). Sistem regulator automatik dengan keluaran berupa besaran seperti temperatur, tekanan, aliran, disebut sistem pengontrolan proses. Pengontrolan proses secara luas digunakan diindustri. Kontroler berfungsi untuk menjaga temperatur agar mendekati titik stel yang berubah. Sistem kontrol terdiri atas: sistem kontrol tertutup (close loop) dilengkapi elemen yang berfungsi sebagai umpan balik (feead back) ditunjukkan dalam Gambar 2.1. Gambar 2.2 adalah gambar sistem kontrol terbuka (open loop control system).

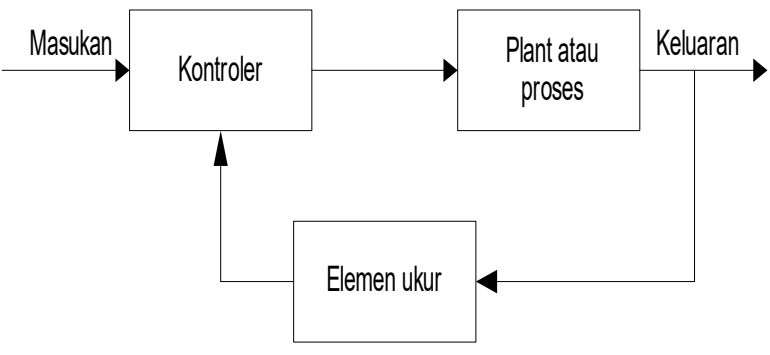

Gambar 2.1. Sistem kontrol lup tertutup (Katsuhiko Ogatha, 1995).

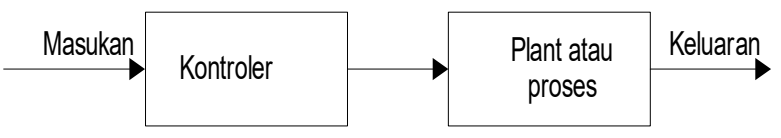

Gambar 2.2. Sistem kontrol lup terbuka (Katsuhiko Ogatha, 1995).

Sistem kontrol lup terbuka (open loop control system) adalah sistem kontrol yang keluarannya (output) tidak bergantung pada saat pengontrolan. Jadi pada sistem kontrol lup terbuka, keluaran tidak diukur atau diumpan balikkan untuk dibandingkan dengan masukkan (input) Sehingga untuk setiap masukkan acuan, terdapat suatu kondisi operasi yang tetap. Jadi ketelitian sistem tergantung pada kalibrasi. (sistem kontrol lup terbuka harus dikalibrasi dengan teliti dan harus menjaga kalibrasi tersebut agar dapat dimanfaatkan dengan baik). Dengan adanya gangguan sistem kontrol lup terbuka dapat digunakan dalam praktek hanya jika hubungan antara masukkan dan keluaran diketahui dan jika tidak terdapat gangguan internal maupun eksternal. 


\subsection{Perbandingan Sistem Kontrol Lup Tertutup dan Lup Terbuka}

Kelebihan sistem kontrol lup tertutup adalah penggunaan umpan balik yang membuat respon sistem relatif kurang peka terhadap gangguan eksternal dan perubahan internal pada parameter sistem. Jadi mungkin dapat digunakan komponen - komponen yang relatif kurang teliti dan murah untuk mendapatkan pengontrolan "plant" dengan teliti, hal ini tidak mungkin memperoleh pada sistem lup terbuka. Dari segi kestabilan, sistem kontrol lup terbuka lebih mudah dibuat karena kestabilan bukan merupakan persoalan utama.

\subsection{Rentangan (range) Suhu Panas Untuk Menetaskan Telur ayam Buras}

Rentangan suhu panas untuk menetaskan telur ayam buras sangat kecil antara 38 derajad celsius sampai dengan 40 derajad celsius. Tentunya membutuhkan mesin tetas yang handal terutama sistem kontrol suhu panas di dalam ruang rak telur mesin tetas telur ayam buras. Sistem kontrol suhu panas yang dimaksud adalah sistem kontrol suhu yang merata dan stabil, hemat energi selama proses penetasan telur ayam buras. Rentangan suhu panas untuk menetaskan telur ayam buras di dalam ruang rak telur mesin tetas ditunjukkan dalam Gambar 2.3.

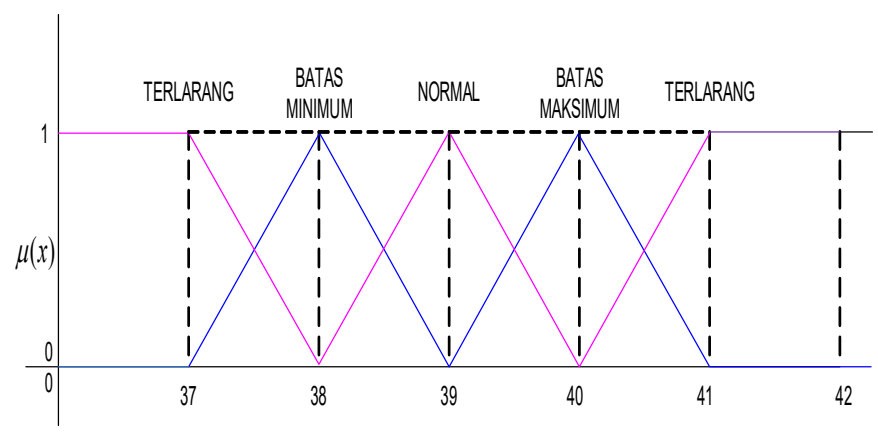

Gambar 2.3. Rentangan suhu normal untuk menetaskan telur ayam buras
1) Perancangan ukuran dan model mesin tetas telur ayam buras dan perancangan rangkaian kontrol suhu panas.

2) Pengujian laboratorium yaitu pengujian untuk mengukur peyebaran dan kestabilan suhu panas didalam ruang rak telur mesin tetas tanpa telur ayam buras dan menggunakan telur ayam buras.

\section{PEMBAHASAN DAN ANALISIS}

\subsection{Data perancangan:}

Data perancangan ukuran mesin tetas telur ayam yaitu:

Panjang $(\mathrm{P})=90 \mathrm{~cm}$.

Lebar $(\mathrm{L})=30 \mathrm{~cm}$.

Tinggi $(\mathrm{T})=32 \mathrm{~cm}$.

A : tampak atas mesin tetas.

B : tampak depan mesin penetas.

C : tampak samping mesin penetas.

Gambar hasil rancangan mesin tetas ditunjukkan dalam Gambar 4.1a, 4.1b, 4.1c, 4.1d, 4.1e, $4.1 \mathrm{f}$. 


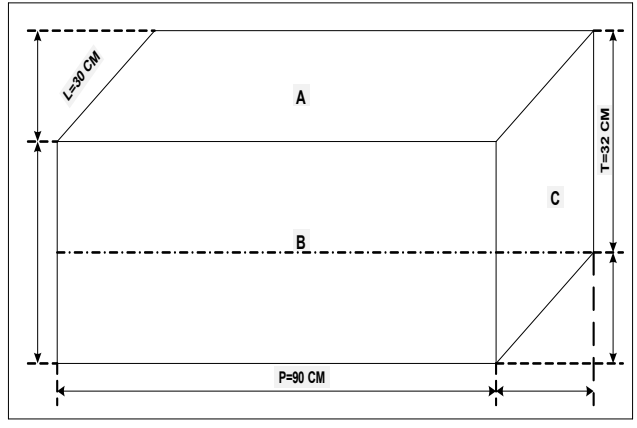

Gambar: 4.1a Ukuran mesin tetas (rancangan)

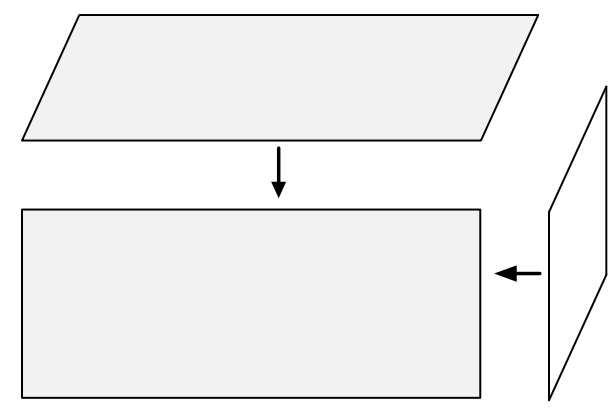

Gambar: 4.1c Model mesin tetas yang akan dibuat (rancangan)

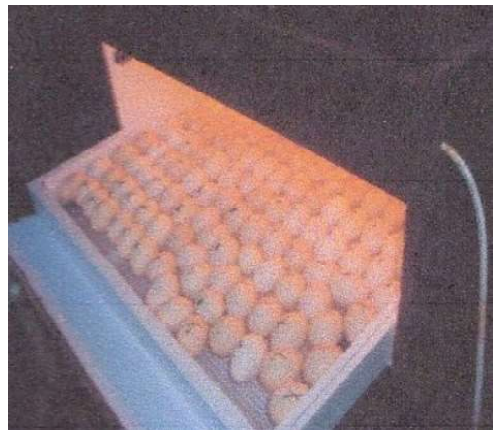

Gambar: 4.1e Telur ayam buras hasil seleksi dimasukkan ke dalam rak telur mesin tetas (implementasi)

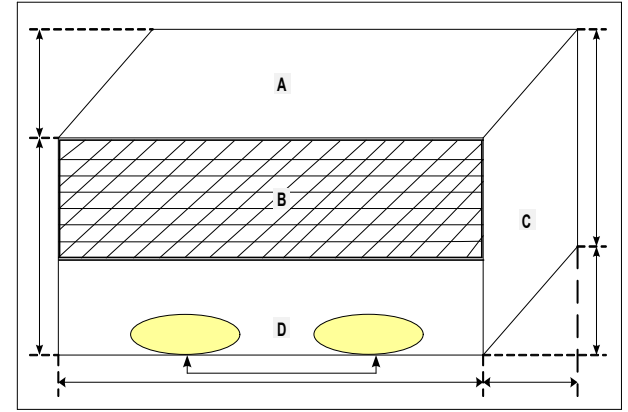

Gambar: 4.1b rak telur (rancangan)

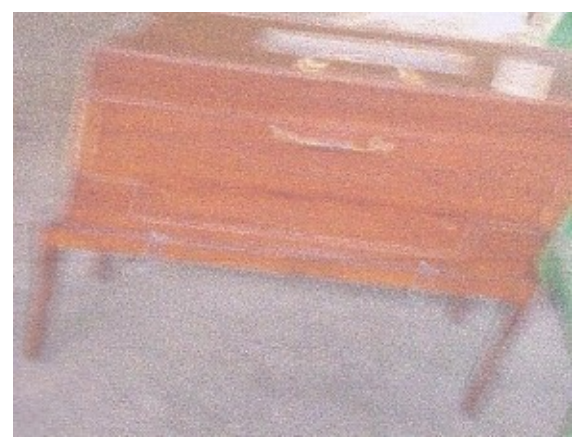

Gambar: 4.1d Model mesin tetas (hasil rancangan)

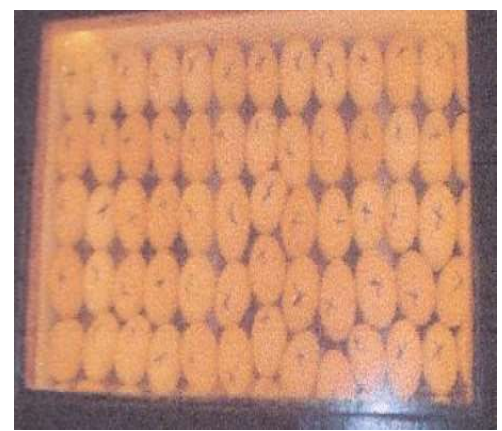

Gambar: 4.1f Telur ayam buras dalam rak telur mesin tetas (implementasi) 


\subsection{Gambar rangkaian kontrol}

Gambar rangkaian kontrol pemanas didalam ruang rak telur mesin tetas ditunjukkan dalam Gambar 4.2a dan gambar rangkaian kontrol suhu panas didalam ruang rak telur mesin tetas ditunjukkan dalam Gambar 4.2b.

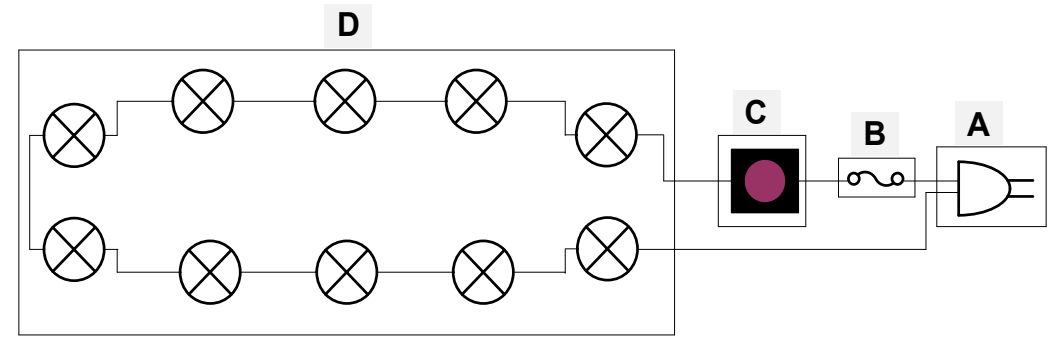

Gambar 4.2a. Rangkaian kontrol suhu panas ruang rak telur mesin tetas telur ayam buras (hasil rancangan).

\subsection{Data Pengujian}

Data pengujian besaran arus listrik yang mengalir dalam rangkaian kontrol suhu panas, suhu panas didalam ruang rak telur mesin tetas hasil penelitian dan suhu ruang pengujian dilakukan tanpa beban (tanpa telura ayam buras) dan dilakukan dengan beban (dengan telur ayam buras) merupakan uji implementasi mesin tetas telur ayam buras hasil penelitian. Data pengujian tanpa beban ditunjukkan dalam Tabel 4.1, data pengujian implementasi ditunjukkan dalam Tabel 4.2.

Tabel 4.1 Data pengujian tanpa beban

\begin{tabular}{|c|c|c|c|}
\hline $\begin{array}{c}\text { Waktu } \\
(\text { menit })\end{array}$ & $\begin{array}{c}\text { Arus } \\
\text { listrik (A) }\end{array}$ & $\begin{array}{c}\text { Suhu ruang } \\
\text { rak telur } \\
\text { mesin tetas } \\
\left({ }^{0} \mathrm{C}\right)\end{array}$ & $\begin{array}{c}\text { Suhu } \\
\text { ruangan } \\
\left({ }^{0} \mathrm{C}\right)\end{array}$ \\
\hline 0 & 0.26 & 36 & 32 \\
\hline 20 & 0.26 & 37.9 & 32.1 \\
\hline 40 & 0.26 & 38.5 & 33 \\
\hline 60 & 0.26 & 40.1 & 33 \\
\hline 80 & 0.22 & 39.5 & 35 \\
\hline 100 & 0.22 & 38.5 & 35 \\
\hline 120 & 0.22 & 37.8 & 33 \\
\hline 140 & 0.23 & 38.2 & 33 \\
\hline 160 & 0.23 & 38.9 & 32.6 \\
\hline 180 & 0.23 & 39.1 & 32.5 \\
\hline 200 & 0.23 & 39.2 & 32.3 \\
\hline
\end{tabular}

\begin{tabular}{|c|c|c|c|}
\hline 220 & 0.23 & 39.1 & 32.1 \\
\hline 240 & 0.23 & 39.1 & 32.1 \\
\hline 260 & 0.23 & 39.1 & 31.9 \\
\hline 280 & 0.23 & 39 & 31 \\
\hline 300 & 0.23 & 39 & 30.6 \\
\hline 320 & 0.23 & 39 & 30.5 \\
\hline 340 & 0.23 & 39 & 30.1 \\
\hline 360 & 0.23 & 39 & 30 \\
\hline 380 & 0.23 & 39 & 30 \\
\hline 400 & 0.23 & 39 & 29.8 \\
\hline 420 & 0.23 & 39 & 29.8 \\
\hline 440 & 0.23 & 39 & 29.7 \\
\hline 460 & 0.23 & 39 & 29.7 \\
\hline 480 & 0.23 & 39 & 29.5 \\
\hline 500 & 0.23 & 38.74 & 29.2 \\
\hline 520 & 0.23 & 38.71 & 29.15 \\
\hline 540 & 0.23 & 38.71 & 29.1 \\
\hline 560 & 0.23 & 38.7 & 29.05 \\
\hline 580 & 0.23 & 38.7 & 29 \\
\hline 600 & 0.23 & 38.7 & 29 \\
\hline 620 & 0.23 & 38.65 & 28.9 \\
\hline 640 & 0.23 & 38.5 & 28.9 \\
\hline 660 & 0.23 & 38.5 & 28.85 \\
\hline 680 & 0.23 & 38.5 & 28.85 \\
\hline 500 & 0.23 & 38.2 & 28.85 \\
\hline 520 & 0.23 & 38.2 & 28.83 \\
\hline 540 & 0.23 & 38.2 & 28.83 \\
\hline
\end{tabular}




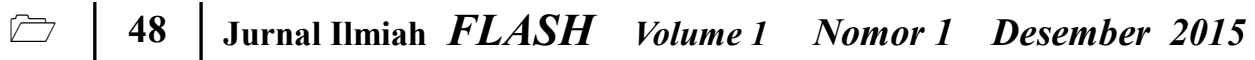

\begin{tabular}{|c|c|c|c|}
\hline 560 & 0.23 & 38.2 & 28.1 \\
\hline 580 & 0.23 & 38.2 & 28.1 \\
\hline 600 & 0.23 & 38.2 & 28.1 \\
\hline 620 & 0.23 & 38.2 & 28 \\
\hline 640 & 0.23 & 38.2 & 28 \\
\hline 660 & 0.23 & 38.2 & 28 \\
\hline 680 & 0.23 & 38.2 & 27.98 \\
\hline 700 & 0.23 & 38.15 & 27.98 \\
\hline 720 & 0.23 & 38.15 & 27.95 \\
\hline 740 & 0.23 & 38.15 & 27.95 \\
\hline 760 & 0.23 & 38.15 & 27.93 \\
\hline 780 & 0.23 & 38.15 & 27.9 \\
\hline 800 & 0.23 & 38.15 & 27.85 \\
\hline 820 & 0.23 & 38.15 & 27.81 \\
\hline 840 & 0.23 & 38.15 & 27.81 \\
\hline 860 & 0.23 & 38.15 & 27.81 \\
\hline 880 & 0.23 & 38.1 & 27.8 \\
\hline 900 & 0.23 & 38.1 & 27.89 \\
\hline 920 & 0.23 & 38.1 & 27.89 \\
\hline 940 & 0.23 & 38.1 & 27.87 \\
\hline 960 & 0.23 & 38.15 & 27.87 \\
\hline 980 & 0.23 & 38.15 & 28 \\
\hline 1000 & 0.23 & 38.25 & 28.2 \\
\hline 1020 & 0.23 & 38.25 & 28.35 \\
\hline 1040 & 0.23 & 38.27 & 28.4 \\
\hline 1060 & 0.23 & 38.27 & 28.47 \\
\hline 1080 & 0.23 & 38.31 & 28.55 \\
\hline 1100 & 0.23 & 38.32 & 28.65 \\
\hline 1120 & 0.23 & 38.35 & 28.78 \\
\hline 1140 & 0.23 & 38.4 & 29.15 \\
\hline 1160 & 0.23 & 38.41 & 28.45 \\
\hline 1180 & 0.23 & 38.5 & 28.85 \\
\hline 1200 & 0.23 & 38.5 & 29.1 \\
\hline
\end{tabular}

Tabel 4.2 Data pengujian kestabilan suhu dengan beban

\begin{tabular}{|c|c|c|c|}
\hline $\begin{array}{l}\text { Waktu } \\
\text { (menit) }\end{array}$ & $\begin{array}{c}\text { Arus } \\
\text { listrik } \\
\text { (A) }\end{array}$ & $\begin{array}{l}\text { Suhu ruang } \\
\text { rak telur } \\
\text { mesin tetas } \\
\left({ }^{0} \mathrm{C}\right)\end{array}$ & $\begin{array}{c}\text { Suhu ruangan } \\
\left({ }^{0} \mathrm{C}\right)\end{array}$ \\
\hline 0 & 0.25 & 37.1 & Suhu ruangan \\
\hline 20 & 0.25 & 37.5 & (derajad celsius) \\
\hline 40 & 0.26 & 37.7 & \\
\hline 60 & 0.26 & .38 .1 & 32 \\
\hline 80 & 0.24 & 37.6 & 32.1 \\
\hline 100 & 0.24 & 37.9 & 33 \\
\hline 120 & 0.24 & 38.1 & 33 \\
\hline 140 & 0.24 & 38.3 & 35 \\
\hline 160 & 0.24 & 38.7 & 35 \\
\hline 180 & 0.24 & 38.7 & 33 \\
\hline 200 & 0.24 & 38.9 & 33 \\
\hline 220 & 0.24 & 38.9 & 32.6 \\
\hline 240 & 0.24 & 39 & 32.5 \\
\hline 260 & 0.24 & 39 & 32.3 \\
\hline 280 & 0.24 & 39.1 & 32.1 \\
\hline 300 & 0.24 & 39.3 & 32.1 \\
\hline 320 & 0.24 & 39.5 & 31.9 \\
\hline 340 & 0.24 & 39.6 & 31 \\
\hline 360 & 0.24 & 39.7 & 30.6 \\
\hline 380 & 0.24 & 39.7 & 30.5 \\
\hline 400 & 0.24 & 39.7 & 30.1 \\
\hline 420 & 0.24 & 39.7 & 30 \\
\hline 440 & 0.24 & 39.8 & 30 \\
\hline 460 & 0.24 & 39.8 & 29.8 \\
\hline 480 & 0.24 & 39.8 & 29.8 \\
\hline 500 & 0.24 & 39.8 & 29.7 \\
\hline 520 & 0.24 & 39.8 & 29.7 \\
\hline 540 & 0.24 & 39.8 & 29.5 \\
\hline 560 & 0.24 & 39.7 & 29.2 \\
\hline 580 & 0.24 & 39.7 & 29.2 \\
\hline 600 & 0.24 & 39.6 & 29.2 \\
\hline 620 & 0.24 & 39.6 & 29.2 \\
\hline 640 & 0.24 & 39.5 & 29 \\
\hline 660 & 0.24 & 39.5 & 29 \\
\hline 680 & 0.24 & 39.5 & 28.9 \\
\hline 500 & 0.24 & 39.2 & 28.9 \\
\hline
\end{tabular}




\begin{tabular}{|c|c|c|c|}
\hline 520 & 0.24 & 39.1 & 28.8 \\
\hline 540 & 0.24 & 39 & 28.8 \\
\hline 560 & 0.24 & 39 & 28.8 \\
\hline 580 & 0.24 & 39 & 28.8 \\
\hline 600 & 0.24 & 39 & 28.8 \\
\hline 620 & 0.24 & 39 & 28.5 \\
\hline 640 & 0.24 & 38.8 & 28.5 \\
\hline 660 & 0.24 & 38.8 & 28.5 \\
\hline 680 & 0.24 & 38.8 & 28.5 \\
\hline 700 & 0.24 & 38.7 & 28.3 \\
\hline 720 & 0.24 & 38.7 & 28.3 \\
\hline 740 & 0.24 & 38.6 & 28.3 \\
\hline 760 & 0.24 & 38.6 & 28.3 \\
\hline 780 & 0.24 & 38.6 & 28.3 \\
\hline 800 & 0.24 & 38.6 & 27.9 \\
\hline 820 & 0.24 & 38.6 & 27.9 \\
\hline 840 & 0.24 & 38.5 & 27.9 \\
\hline 860 & 0.24 & 38.5 & 27.9 \\
\hline 880 & 0.24 & 38.5 & 27.7 \\
\hline 900 & 0.24 & 38.5 & 27.7 \\
\hline 920 & 0.24 & 38.4 & 27.7 \\
\hline 940 & 0.24 & 38.4 & 27.6 \\
\hline 960 & 0.24 & 38.4 & 27.6 \\
\hline 980 & 0.24 & 38.4 & 27.6 \\
\hline 1000 & 0.24 & 38.4 & 27.6 \\
\hline 1020 & 0.24 & 38.4 & 27.5 \\
\hline 1040 & 0.24 & 38.4 & 27.5 \\
\hline 1060 & 0.24 & 38.4 & 27.5 \\
\hline 1080 & 0.24 & 38.5 & 27.7 \\
\hline 1100 & 0.24 & 38.6 & 27.7 \\
\hline 1120 & 0.24 & 38.6 & 27.8 \\
\hline 1140 & 0.24 & 38.8 & 27.8 \\
\hline 1160 & 0.24 & 38.9 & 27.9 \\
\hline 1180 & 0.24 & 39 & $27 ; 9$ \\
\hline 1200 & 0.24 & 39.2 & 28.3 \\
\hline
\end{tabular}

\section{KESIMPULAN DAN SARAN}

\subsection{Kesimpulan}

Berdasarkan data hasil pengujian, maka kesimpulan hasil penelitian yaitu :

1) Model mesin penetasan telur ayam buras hasil penelitian suhu panas didalam ruang rak telur mesin tetas menunjukkan suhu yang cukup stabil.
2) Sangat hemat energi karena hanya terserap 50,6 watt mampu menetaskan telur ayam buras sejumlah 100 sampai dengan 105 butir telur ayam buras

3) Daya tetas optimal dapat mencapai $90 \%$

\subsection{Saran}

Berdasarkan pengalaman peneliti, maka sarannya sebagai berikut :

1) Untuk mencapai suhu yang stabil berkisar antara $38 \mathrm{o}-40 \mathrm{oC}$ pengaturan arus listrik perlu dilakukakan secara bertahap untuk mendapatkan nila yang sesuai supaya suhu panas tidak terlalu dingin atau terlalu panas

2) Telur ayam sebaiknya pesan langsung dari peternak ayam, jangan beli yang sudah ada dipasar karena telur ayam belum tentu masih baik atau kadang sudah terkena basah mengakibatkan tidak terjadi proses penetasan

3) Termometer gunakan yang digital khusus untuk thermometer temperatur panas.

\section{DAFTAR PUSTAKA}

J. Michael Jacob,1989. Industrial Control Electronics Printice - Hall International, INC U.S.A., Mexico.

Katsuhiko Ogata, 1984. Teknik Kontrol Automatik, Penerbit Erlangga Jakarta.

Randall Shaffer, 2007. Fundamental of power electronics with matlab Randall shaffer Charles River Media, Boston, Massachusetts.

Suyamto, Yusuf Aziz Amrullah dkk, 2008. Rancang Bangun dan Analisis Perangkat Telemetri Suhu dan Cahaya Menggunakan Amplitudo Shift Keying (ASK) Berbasis PC, STTN Batam.

Vishay, 2012. http//wikipedia Resistor dan variable resistor. 